\title{
Development of Community-based Disaster Prevention and Mitigation Program for Volunteer Leaders of Villages in Disaster-prone Area of Bangladesh
}

\author{
Masako Saito $^{1}$, Mariko Ohara ${ }^{2}$, Yoshiko Tsukada ${ }^{3 *}$, Mir Karim Abdula ${ }^{4}$ and Sonali Rani Das ${ }^{4}$ \\ ${ }^{1}$ Department of Nursing,Tokyo Kasei University, 2-15-1, Inariyama, Sayama City, Saitama Pref. 350-1398, Japan \\ ${ }^{2}$ Japanese Red Cross College of Nursing, 4 chome 1-3, Hiroo, Shibuya, Tokyo, 150-0012, Japan \\ ${ }^{3}$ School of Nursing, Saku University, 2384 Iwamurata, Saku City, Nagano, 385-0022, Japan \\ ${ }^{4}$ Bangladesh Red Crescent Society (BDRCS), 684-686, Bara Maghbazar, Dhaka 1217, G.P.O. Box 579, Bangladesh
}

\begin{abstract}
The aim of this study was to develop a community-based disaster prevention and mitigation program for volunteer leaders of villages in disaster-prone areas of Bangladesh. The action research method was used in this study. The target area was 10 villages. A needs survey for disaster prevention and mitigation was conducted among 100 village volunteer leaders (10 leaders from each village). Based on survey results, disaster prevention and mitigation training programs were developed and training contributed to enhancing volunteer leaders' knowledge and techniques. In order to implement disaster prevention and mitigation activities in the community, the cooperation of the Bangladesh Red Crescent Society (the local counterpart in this study) was vital Follow-up programs were modified according to the needs of the target area. Collaborative community-based activities conducted together with municipalities and NPOs will have to be empowered to continue disaster prevention and mitigation activities in the area.
\end{abstract}

\section{Publication History:}

Received: March 30, 2017

Accepted: June 17, 2017

Published: June 19, 2017

Keywords:

Bangladesh, Disaster-prone country, Community, Disaster volunteer leaders, Bangladesh Red Crescent Society, Maternal and Child Health Center

\section{Introduction}

Japanese researchers planned to apply a research method developed in Japan for disaster-prone areas in Bangladesh. This method was community-based triage for affected vulnerable people in a disaster which will be taught to disaster volunteer leaders.

The People's Republic of Bangladesh (hereafter "Bangladesh") is a densely populated country with the world 8th world largest population of 164 millio $^{1)}$ people. Bangladesh's birth rate is 20.07 per $1,0001^{1)}$, which is relatively-high in the Asian region. The ratio of children under the age of 5 is high at $10.6^{1}$. Also, Bangladesh has the world's fifth-highest disaster risks ${ }^{2}$. Natural disasters such as flood, high tides, and tornadoes have occurred often. In 1970, a cyclone that struck the Bay of Bengal caused the world's worst damage with 300,000 fatalities $^{3)}$, while in 1991, another cyclone claimed the lives of 138,000 people $^{4)}$. And even during quiet periods, people have been suffering in their daily lives by retained sea water called "a creeping disaster".

Bangladesh Red Crescent Society (“BDRCS”) runs 56 Maternal and Child Health Center ("MCH Center") through Bangladesh These centers provide primary health care services. Each center has a community midwife, an assistant midwife and two health promoters who work together with community leaders and volunteers.

At researchers' university (Japanese Red Cross College of Nursing), disaster education project was implemented from April 1, 2011 to March 31, 2014. In this project, research fellows from Asian disasterprone countries (Bangladesh, Indonesia and Thailand) were invited to undergo training in disaster nursing. As a result, the research fellows were able to achieve their objectives by developing their own disaster nursing textbooks and educational materials. Research fellows from Bangladesh became the counterparts in this project.

This is the report on items from 2014 to 2016 marked on action research in developing and implementing the program (Figure 1).

\section{Methods}

\section{Qualitative- descriptive study: Action research}

As the first step of this study, researchers visited target areas and conducted a prior survey to study village leaders' knowledge and awareness of disaster prevention and mitigation activities in the areas. The next step was to apply the community-based triage method developed in Japan for Bangladesh. Researchers and counterpart personnel developed a program that took into consideration disaster culture and living habit. The third step was implementation of the programs. The forth step was to evaluate behavioral changes after training and modify the content of next training. According to Tsutsui 's Action Research Theory, action research takes a participatory approach, where researchers and persons involved in the community work together. It is a democratic method that produces not only academic result, but also changes that can influence the society itself $^{4)}$. Moreover, Holter and Schwart-Barcott [1] described the four advantages of action researches: Collaborative works between researchers and community individuals (cooperators); a practical problem-solving method; changes by implementation; and building of theory. Lathlean [2] started the following three advantages: intervention. Close follow-up of the situation; and creation of logical result rather than statistics. Accordingly, the researchers decided to use the action research [3-5].

"Corresponding Author: Dr. Yoshiko Tsukada, School of Nursing, Saku University, 2384 Iwamurata, Saku City, Nagano, 385-0022, Japan; E-mail: y-tsukada@saku.ac.jp

Citation: Saito M, Ohara M, Tsukada Y, Abdula MK, Das SR (2017) Development of Community-based Disaster Prevention and Mitigation Program for Volunteer Leaders of Villages in Disaster-prone Area of Bangladesh. Int J Nurs Clin Pract 4: 240. doi: https://doi.org/10.15344/2394-4978/2017/240

Copyright: @ 2017 Saito et al. This is an open-access article distributed under the terms of the Creative Commons Attribution License, which permits unrestricted use, distribution, and reproduction in any medium, provided the original author and source are credited. 
Citation: Saito M, Ohara M, Tsukada Y, Abdula MK, Das SR (2017) Development of Community-based Disaster Prevention and Mitigation Program for Volunteer Leaders of Villages in Disaster-prone Area of Bangladesh. Int J Nurs Clin Pract 4: 240. doi: https://doi.org/10.15344/2394-4978/2017/240

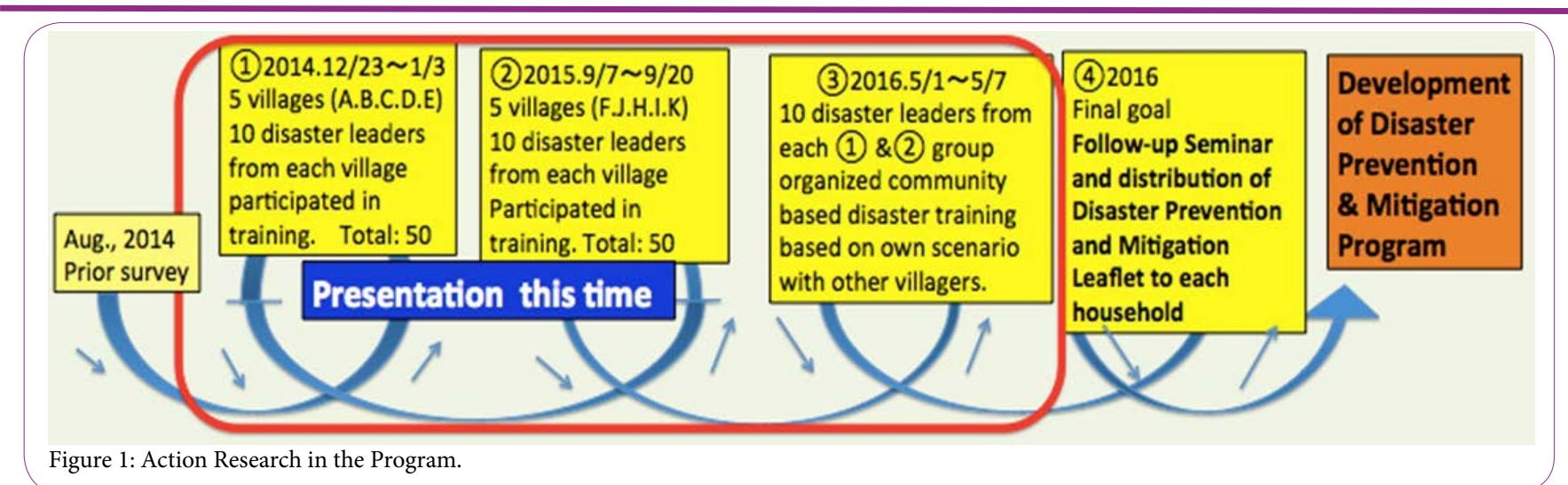

Aim: Development of a community-based disaster prevention and mitigation program for volunteer leaders of villages in disasterprone areas of Bangladesh Definition of terms: Village-level leaders means MCH Center stall (community midwife, assistant community midwife and health promoters), and village leaders and disaster volunteer leaders who work with them [6].

Period: December 23, 2014 to May 7, 2016

Cooperators: Disaster volunteer leaders of 10 target villages covered by two $\mathrm{MCH}$ Centers in Khulna district in Bangladesh. The four counterparts in the study were two BDRCS officers and two $\mathrm{MCH}$ Center staff.

\begin{tabular}{|c|c|c|}
\hline \multirow{5}{*}{ average age 26.6} & age 15 19 & 10 \\
\hline & age $20 \sim 29$ & 64 \\
\hline & age 30 39 & 19 \\
\hline & age $40 \sim 49$ & 6 \\
\hline & age 50 and more & 1 \\
\hline \multirow[t]{2}{*}{ gender } & male & 49 \\
\hline & female & 51 \\
\hline \multirow[t]{6}{*}{ profession } & housewife & 34 \\
\hline & student & 31 \\
\hline & farmer & 20 \\
\hline & shopkeeper & 5 \\
\hline & teacher & 2 \\
\hline & unknown & 8 \\
\hline \multicolumn{3}{|l|}{ volunteer } \\
\hline \multirow[t]{3}{*}{ activities } & Yes & 49 \\
\hline & No & 51 \\
\hline & & $\mathrm{n}=49$ \\
\hline \multicolumn{3}{|l|}{ kind of volunteer } \\
\hline \multirow[t]{4}{*}{ activities } & $\mathrm{CCV}$ & 19 \\
\hline & RREW-CVS & 4 \\
\hline & others & 6 \\
\hline & unknown & 20 \\
\hline \multicolumn{3}{|c|}{ CCV: Community Cyclone Volunteer } \\
\hline \multicolumn{3}{|c|}{ RREW: Risk Education Empowerment for Women } \\
\hline \multicolumn{3}{|c|}{ CVS: Community Volunteer Service } \\
\hline
\end{tabular}

Table1:Description of Participants $n=100$
Ethical consideration: The study was authorized by ethical committee, No. 2014-69 of the Japanese Red Cross College of Nursing. The study was described to cooperators in Bengali and English and carried out after obtaining their agreement.

\section{Findings}

Implementation of community-based disaster prevention and mitigation program

Period: Dec.2014 Sep. 2015

Method: Ten villages of Mushigong Union, Satkhira Province, were targeted. A total of 100 disaster volunteer leaders (10 per village, average pop.2,000) participated. The 100 participants divided into four groups. Each group participated in a two-day seminar on communitybased disaster prevention and mitigation. Before the seminar, questionnaire was distributed to participants to test their knowledge of disaster prevention. Participants' attitude and commitment to seminar program were also observed by researchers [7].

Description of participants: 100 disaster volunteer leaders from 10 villages participated. There were 49 males and 51 females, and the average age of participants was 26.6. Their professions were housewives, students, farmers, shop keepers and teachers. Forty-nine of them had participated in volunteer activities before, while 51 of them had not.

Contents of community-based disaster prevention and mitigation program developed:

Counterparts of this study (two officers of BDRCS, and two $\mathrm{MCH}$ Center midwives) acted as instructors in English and Bengali. A oneday, 6-hourlong training seminar was given to disaster volunteer leaders, and a two-day training seminar of 3 hours each day was given to sub-disaster volunteer leaders. The contents of the seminar was to create a hazard map for each village, and group discussion to decide topics for disaster programs desired. Major topics listed were:

Health after disaster (treatment of diarrhea, skin problems); 2. Awarning system; 3. First aid in disaster; 4 . Knowledge of disasters; 5. shelter management [8]; 6. Items to stock pile for disaster response; 7. Transportation of ill or injured persons, Based on the result, the researchers created seminar contents and simulations.

Pre-seminar questionnaire findings: 
Citation: Saito M, Ohara M, Tsukada Y, Abdula MK, Das SR (2017) Development of Community-based Disaster Prevention and Mitigation Program for Volunteer Leaders of Villages in Disaster-prone Area of Bangladesh. Int J Nurs Clin Pract 4: 240. doi: https://doi.org/10.15344/2394-4978/2017/240

- It became clear that $99 \%$ of the participants had experienced natural disaster. The most common was cyclones, named by $78 \%$. All participants had experienced some type of natural disaster such as a cyclone, tornado, flood or earthquake.

- Problems encountered during a disaster: drinking water, foods, and (damage to) houses, in that order. Health problems, in descending order of prevalence, were injuries, diarrhea, skin problems and pneumonia.

- $\quad 73 \%$ of participants had participated in disaster prevention education offered by NGOs in the past. Disaster prevention activities they were currently carrying out included confirming shelter locations, giving villagers disaster information and stockpiling supplies.

- $48 \%$ of participants has received disaster prevention education, while $52 \%$ were learning about disaster for the first time.

- Prior to the seminar, participants had attended disaster prevention education given by BDRCS and 2 . Caritas, an NGO. Kalitas. Their answers about information needed for disaster prevention education were building disaster-resistant houses on high ground, learning about disaster prevention, and being able to reach a shelter safely.

- $88 \%$ were familiar with the expression "people vulnerable to disaster" who need help" in disaster, and $40 \%$ knew what types of people were vulnerable. After the seminar, participants answered that the Content of the seminars had been clear.

- $100 \%$ of participants answered that the seminars were helpful for self-help and mutual-help in disasters.

- The most beneficial practical information that participants learned in the seminars were 1. first aid, 2. disaster knowledge, 3. warning systems. Many participants commented that they want to share the knowledge and skills they had acquired with villagers and communicate this at village meeting.

Discussion of the community-based disaster support program developed

- In the post-seminar questionnaire, participants indicated that not all villagers knew about disaster warning system and they lacked disaster prevention knowledge. Therefore, they tried to disseminate disaster information to villagers through simulation and checked shelters. Disaster volunteer leaders had received disaster prevention training but not yet disseminated their knowledge among villagers. Further, during rainy season, retained seawater often caused flooding, but villagers did not recognize this as a disaster. For these reasons, it was recognized that ongoing education for village disaster volunteer leaders of villages was needed in order to spread disaster prevention information among villagers.

- Based on findings from the questionnaires and observation of participants' attitudes, researchers confirmed strong needs for education in disaster prevention and mitigation. The key point was how to develop community-based disaster prevention education program that would become ingrained in the community and gain villagers' positive involvement. This seminar program was based on needs of disaster volunteer leaders. They learned about first aid and followed the simulations with strong interest. The researchers believe that sustained cooperation with counterparts is essential for sustaining these community-based disaster activities. Programs for volunteer leaders should be developed based on progress made in disseminating information among villagers.

\section{Community based simulationdrill}

In the post-seminar questionnaire, participants indicated that not all villagers knew about disaster warning system and they lacked disaster prevention knowledge. Therefore, they tried to disseminate disaster information to villagers through simulation and checked shelters. Disaster volunteer leaders had received disaster prevention training but not yet disseminated their knowledge among villagers. Further, during rainy season, retained seawater often caused flooding, but villagers did not recognize this as a disaster. For these reasons, it was recognized that ongoing education for village disaster volunteer leaders of villages was needed in order to spread disaster prevention information among villagers.

Based on findings from the questionnaires and observation of participants' attitudes, researchers confirmed strong needs for education in disaster prevention and mitigation. The key point was how to develop community-based disaster prevention education program that would become ingrained in the community and gain villagers' positive involvement. This seminar program was based on needs of disaster volunteer leaders. They learned about first aid and followed the simulations with strong interest. The researchers believe that sustained cooperation with counterparts is essential for sustaining these community-based disaster activities. Programs for volunteer leaders should be developed based on progress made in disseminating information among villagers.

Period: May, 2016

Method: 20 disaster volunteer leaders (2 disaster volunteer leaders per village out of the 100 trainees of the seminar were selected. Among them, 10 leaders were responsible for five villages each and simulations were carried out at two venues (the square in front of a municipal office and a schoolyard). After the simulation, researchers evaluated whether these disaster volunteer leaders could play the role of community disaster volunteer leaders.

Cooperators: 20 disaster volunteer leaders out of the 100 seminar trainees. 
Citation: Saito M, Ohara M, Tsukada Y, Abdula MK, Das SR (2017) Development of Community-based Disaster Prevention and Mitigation Program for Volunteer Leaders of Villages in Disaster-prone Area of Bangladesh. Int J Nurs Clin Pract 4: 240. doi: https://doi.org/10.15344/2394-4978/2017/240

Page 4 of 5

Simulation drill: The 20 disaster volunteer leaders were divided into two groups. Each group created a scenario of a cyclone for this simulation drill. In each group, leaders took responsibility for five major activities (guiding evacuation, rescuing the injured, transporting the injured and giving first aid and overall assessment of simulation drill). Here is the scenario of one drill for reference.

Result of simulation drill

$<$ Case 1 Scenario $>$

Venue of simulation drill Schoolyard of Mathurapur Primary School, Jellakali village

The third floor of the Primary School is designated a cyclone shelter.

Disaster Information by radio: A large scale cyclone occurred in Shatkira Province, and it will reach Jellakali village within 30 minutes.

Participants 10 disaster volunteer leaders and 50 villagers from five villages

- Fifty village participants cooperated with the 10 disaster volunteer leaders, guiding villagers to the shelter and rescuing the injured. Most of the villagers were past trainees out of the 100 participants. First aid was provided by the community assistant midwife who worked for MCH Center nearby. The 100 disaster volunteer leaders who finished the training seminar divided into two groups to organize simulation drill.

- Disaster volunteer leaders created a scenario making use of the concepts and knowledge they studied and organized communitybased disaster prevention simulation drills.

- Judging from disaster volunteer leaders' answers to the questionnaire after the simulation drill and observation of their attitude, researchers judged that the volunteers had acquired sufficient ability.

- After the simulation drill, when researchers asked the disaster volunteer leaders plus 10 villagers about effectiveness of the simulation drill, all of them answered that it was an effective drill for themselves and the villagers and that they could translate their knowledge for actions.

Discussion of the simulation drill

- Through this simulation practice, it became clear that disaster volunteer leaders must acquire skills or knowledge in five area: collecting information, guiding evacuation, transporting the injured, administering first aid, and assessing conditions (Figure 2). For the next step following assessment, disaster volunteer leaders must think of whether the injured need to be transferred to an $\mathrm{MCH}$ Center or a hospital or whether first aid is sufficient.

- In the simulation drill, leaders had 30 minutes to act before cyclone would reach the village, so villagers are needed to move quickly. More drills are needed as far as providing assistance to vulnerable neighbors and getting them to a cyclone shelter is concerned.

- Regarding transporting the injured, this was done properly using stretchers as the volunteers had practiced in training program. Rescue of a drowning person and getting a person down from a tall tree were done promptly. First aid was well performed. Many villagers came to see the simulation drill, an indication that many villagers were interested in such simulation drills.

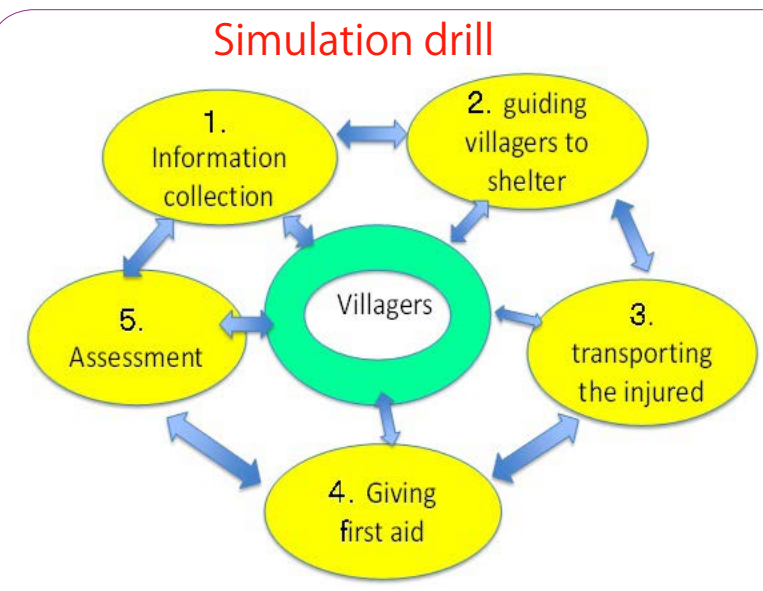

Figure 2: Five items of study for disaster volunteer leaders.

Two issues were came up in the simulation drill. One was that, in the drill, it was impossible to guide villagers' livestock to the shelter. In the next simulation drill, practice in evacuating livestock must be included. As a Japanese proverb says, "disaster strikes just when people have forgotten about the previous one," so simulation drills should continue to be held once a year in future. The other issue was for disaster volunteer leaders and neighbors to know in advance who would help which vulnerable people. These two points are also issues in Japan.

\section{Conclusion}

This study was able to identify the study needs of disaster volunteer leaders. Based on these needs, researchers and counterparts created a training seminar program and trained disaster volunteer leaders, which helped improve disaster volunteer leaders' knowledge and skills. However, this kind of program and training for disaster volunteer leaders must be continued in order for it to contribute to community-based disaster prevention and mitigation. Researchers overseas can only offer limited support, due to distance, the language barrier, differences in culture and customs, and funding. Therefore, researchers must continue working together and cooperating with counterparts to refine the content of the program and it implementation, and also involve the administrative authorities and NGOs to empower community for disaster preparedness.

\section{Competing Interests}

The authors declare that they have no competing interests.

\section{Acknowledgements}

On behalf of researchers, we would like to express the deepest appreciation for kind cooperation of the Bangladesh Red Crescent Society, disaster volunteer leaders and cooperators of the community.

\section{Funding}

The study was funded by the Ministry of Education, Culture, Sports, Science and Technology-Japan.

\section{References}

1. Holter IM, Schwartz-Barcott D (1993) Action research: What is it? How has it been used and how can it be used in nursing?. Journal of Advanced Nursing 18: 298-304. 
Citation: Saito M, Ohara M, Tsukada Y, Abdula MK, Das SR (2017) Development of Community-based Disaster Prevention and Mitigation Program for Volunteer Leaders of Villages in Disaster-prone Area of Bangladesh. Int J Nurs Clin Pract 4: 240. doi: https://doi.org/10.15344/2394-4978/2017/240

2. Lathlean J (1994) Choosing an appropriate methodology. In Buckeldee J McMahon R (eds.), The research experience in nursing. pp. 31-46, London, Chapman and Hall.

3. CAI Word Fact Book 2012

4. U.S. Ansus Bureau, International Data Base 2013

5. World Bank 2010: Disaster Management Bureau / Government of Bangladesh 2010

6. Tsutsui M (2010) Introduction for Action Research. To the new step for nursing researches. Life Support Co. Ltd..48

7. Hart E, Bond M (1995) Action research for health and social care: A guide to practice. pp. 36-58, Philadelphia, Open University Press.

8. Kiefer CW(2010) Action Research for culture and Nursing. Igaku Shoin Co. Ltd. 